\title{
КОНСТИТУАЛИЗАЦИЯ ПРЕДМЕТА АДМИНИСТРАТИВНОГО ПРАВА СОВРЕМЕННОЙ РОССИИ
}

\author{
Воронов Алексей Михайлович \\ Д.ю.н., профессор, г.н.С., ФГКУ «Всероссийский \\ научно-исследовательский институт МВД России» \\ alex_voronoff@mail.ru
}

\section{CONSTITUTIONALIZATION OF THE SUBJECT OF ADMINISTRATIVE LAW OF MODERN RUSSIA}

A. Voronov

Summary. On the basis of an analysis of the current legislation, the law enforcement practice of the public administration, as well as a study of public administration issues, the author states that the public authorities carry out the tasks and functions of the State in all spheres of life. It is this activity, carried out on the basis and in accordance with the law on the protection of human and civil rights and freedoms, as well as the implementation of state tasks in the socio-economic, law enforcement and other fields, that is called public administration and is carried out in the context of the constitutionalization of the subject of administrative law of modern Russia, regulating public relations from purely managerial - state-power (imperative) prior to emergency (service) relations for the provision of public services to citizens, as well as the restoration of violated citizens' rights by unlawful actions of public administration officials.

Keywords: constitutionalization, subject of administrative law, public administration, public power, rights and freedoms of citizens, public services, service relations.

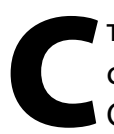

тановление и развитие российской государственности очень интенсивно и динамично. С принятием Конституции Российской Федерации 1993 г., положения которой стали фундаментальной основой становления российской государственности, наша страна встала на совершенно новый путь своего развития, а именно построение социального, демократического, правового государства, в котором права и свободы граждан являются приоритетными, а их реализации основной задачей государства. Действующая Конституция РФ произвела революционные перемены - она закрепила власть народа, чего в предыдущих конституциях советского государства не было.
Интенсивно развиваются все сферы жизнедеятельности государства: социальная, экономическая, политическая, правоохранительная и др. В стране перманентно проводится административная реформа: пересмотрены и реально реализованы в ряде законов положения, касающиеся контрольной и надзорной деятельности, идёт оптимизация и реформирования институтов развития, проводится цифровая трансформация в социальной, экономической и иных сферах, в стадии завершения находится работа по реформированию административно-деликтного законодательства.

Особо следует отметить внесения в 2020 г. поправок в Конституцию Российской Федерации, инициирован- 
ных президентом РФ В. Путиным, положения которых направлены на развитие демократических устоев российской государственности, развитие и совершенствование мер обеспечения законных интересов россиян, а также оптимизацию системы и структуры органов публичной власти. Новые положения закреплены в Основном законе и нашли свое развитие в более чем 140 нормативных правовых актах. Новая редакция Основного закона стала импульсом для реализации принципов социального государства во всех сферах жизнедеятельности.

Законодатель вводит новое понятие - публичная власть, интегрирующее в себе «федеральную», «региональную» и «местную (муниципальную)» власти, закрепляя принцип единства системы публичной власти, призванной служить интересам многонационального народа России. При этом следует обратить внимание, что согласно ч. 3 ст. 132 Конституции РФ органы местного самоуправления и органы государственной власти входят в единую систему публичной власти в Российской Федерации и осуществляют взаимодействие для наиболее эффективного решения задач в интересах населения, проживающего на соответствующей территории.

На наш взгляд, давно назрела необходимость закрепления в Конституции принципа единства системы публичной власти. Доктринально данный принцип формулировался и отстаивался в российской науке на протяжении довольного длительного периода времени, при этом авторы отмечали, что органы публичной власти должны служить интересам многонационального народа России. Такое служение интересам многонационального народа Российской Федерации должно выражаться, прежде всего, в принятии органами публичной власти нормативно-правовых актов и проведении внутренней политики, направленной на защиту интересов российских граждан, защиту их конституционных прав, свобод и законных интересов. Иными словами, публичная власть должна выступать политическим гарантом защиты интересов российских граждан и гражданского общества в целом.

Многие ученые поддерживают такую позицию, мотивируя тем, что до Конституционной реформы система публичного управления была разорвана: обособлено существовало и реализовывалось государственное управление на федеральном и уровне субъектов федерации, а также местное самоуправление на муниципальном уровне. Однако следует отметить, на наш взгляд публичная власть подразумевает не только управление - государственное и местное самоуправление, данная категория гораздо шире и включает в себя еще довольно обширный блок правоотношений, составляющий предмет современного административного права, о котором будет прописано далее.

В развитие заявленной проблематики представляется целесообразным более детально рассмотреть некоторые новые термины, которые интегрированы в правовую действительность, среди прочих - новая обобщающая категория «публичная власть», «система публичной власти».

Вновь обращаясь ст. 132 Основного закона уместно отметить, что органы местного самоуправления и органы государственной власти не составляют, а входят в единую систему публичной власти. Такая же позиция усматривается в Федеральном законе от 8 декабря 2020 г. № 394-Ф3 «О Государственном Совете Российской Федерации» [3], принятом в развитие поправок к Конституции РФ, в ст. 2 которого дана трактовка понятия именно единой системы публичной власти, под которой понимаются федеральные органы государственной власти, органы государственной власти субъектов Российской Федерации, иные государственные органы, органы местного самоуправления в совокупности.

Здесь следует отметить, что в теории права существуют системообразующие теоретические конструкции, при этом категория «система» трактуется как совокупность взаимообусловленных и взаимоувязанных элементов, строящихся на единых принципах. При таком подходе единство закреплено в самом понятии системы, в связи с чем словосочетание «единая система» на первый взгляд представляется не совсем уместным.

Думается здесь следует определить, что же обусловило законодателя прописать такой термин. На наш взгляд побуждающим мотивом стал новый подход к методологии правового регулирования именно в отраслевую составляющую. В данном определении дан перечень органов власти - федеральных органов, органов государственной власти субъектов Российской Федерации, а также органов местного самоуправления, при этом также определены цели, которые поставлены перед ними и что самое важное - формы реализации, способы с помощью которых эти цели должны быть достигнуты, базовой основополагающей из которых является именно взаимодействие во всех его многообразиях.

Также следует обратить внимание на положение о том, что органы государственной власти входят в систему публичной власти, а не образуют ее. При таком подходе следует отметить, что в этой системе есть еще какой-то элемент, который образует ее. На наш взгляд основу этой системы публичной власти составляет система народной власти, именно народовластие. При 
этом согласно ст. 3 Конституции РФ носителем суверенитета и единственным источником власти в Российской Федерации является ее многонациональный народ. Народ осуществляет свою власть непосредственно, а также через органы государственной власти и органы местного самоуправления.

Термин единая система публичной власти несет в себе политическое наполнение. Политика здесь определяет те новые цели, которые закрепил законодатель и термин «единый» непосредственно влияет на саму систему публичной власти. К сожалению, законодатель не прописал институты гражданского общества как основополагающие в системе публичной власти.

Думается все же нацеленность конституционных поправок направлена на то, чтобы все уровни органов публичной власти и институтов гражданского общества работали как партнеры. Закрепление вопросов взаимодействия и различных партнерских форм на конституционном уровне, закрепление институтов гражданского общества позволяет констатировать, что идея сотрудничества является основополагающей в деятельности публичной власти в контексте новой редакции Основного закона.

В научном сообществе ученых-административистов, да и не только, ведется дискуссия в которой рассматриваются проблемы конституционализации современного административного права и административно-правовой науки в целом, как одного из важнейших факторов их развития, при этом анализируются предлагаемые подходы к изменению парадигмы административного права, раскрывается сущность новых терминов, интегрированных в правовую действительность, среди которых новые обобщающие категории «публичная власть», «система публичной власти», определяются новые методологии исследования конституционализации предмета науки административного права современной России на основе цифровой трансформации системы управления путем новых, инновационных подходов, основанных на цифровых технологиях.

Представители науки административного права обсуждают нововведения в рамках публикаций в журналах и иных периодических изданиях, а также в рамках международных форумов, научно-практических конференций, среди них - VI ежегодные Саратовские административно-правовые чтения «Публичная власть в современной России: проблемы и перспективы» СГЮА; международная конференция: «Актуальные проблемы административного и административно процессуального права (Сорокинские чтения)» Санкт-Петербургский университет МВД России 2021 г.; международная конференции: «Публичная власть: новое измерение» проводимая в МГЮА им. О.Е. Кутафина 9 апреля 2021 г. в рамках VIII Московского юриди- ческого форума «Социально-экономическое развитие и качество правовой среды», к сожалению проводимых в режиме видео конференции, в связи с захлестнувшей не только Российскую Федерацию, а также весь мировой социум пандемии коронавируса COVID-19.

По устоявшейся доброй традиции, как правило, ведущие ученые-административисты обсуждают сложившиеся перед наукой административного права проблемы в стенах «кузницы» юридической науки Московском государственном юридическом университете им. О.Е. Кутафина.

Заслуживающими внимания и представляющими несомненный научный интерес стали выступления 9 апреля 2021 г. в рамках VIII Московского юридического форума уважаемой профессуры: мэтра административно-правовой науки Л.Л.Попова, заведующей кафедрой конституционного права МГЮА им. О.Е. Кутафина В.В. Комаровой, декана юридического факультета Воронежского государственного университета Ю.Н. Старилова и многих других ученых.

Среди прочих, представляется целесообразным обратить внимание на доклад профессора Ю.Н. Старилова: «Станет ли «публичная власть» прочной основой для понимания государственного управления и модернизации системы правового регулирования публичной администрации?», который в рамках своего содержания отражает основные моменты прописанной выше проблематики.

Рассматривая публичную власть в управленческом, административно-правовом измерении, уважаемый профессор констатирует, что данный термин давно уже вошел в оборот юристов, при этом следует отметить, что справедливость этих суждений была подтверждена и нашла свою реализацию в новой редакции Основного закона.

На риторический вопрос - как измерить публичную власть, как оценить ее достоинства, автор совершенно справедливо отвечает - именно с позиции принципов правового государства, принципов определенности права, при этом отмечая, что если нововведения, новые правовые категории не вносят правовую определенность, то тогда и начинается полемика, научная дискуссия. Правовое измерение публичной власти следует вести с самых важных правовых принципов, в частности, с позиции административно-правовых, управленческих и иных публичных отношений. Как нами отмечалось ранее, данной терминологией ученые-административисты оперировали и до введения института публичной власти - публичная администрация, публичный порядок, публичное администрирование, публичное управление, публичная служба и т.п. 
По мнению профессора Ю.Н. Старилова публичность, публичная власть - эти правовые категории являются достижением теории, красивыми университетско-профессорскими терминами, однако как обстоят дела на практике, что дает публичная власть в контексте правового регулирования для улучшения системы публичного управления, для того чтобы публичная администрация была более эффективной - вопрос остается открытым. Какие закономерности прослеживаются с момента принятия поправок, какая практика в развития законодательства будет в последующем пока не известно. В настоящее время потенциал публичной власти остался не раскрыт должным образом.

По мнению автора настоящих строк следует дополнить умозаключения уважаемого Ю.Н. Старилова в том, что публичность, публичная власть являются не только достижением теории, красивыми университетско-профессорскими терминами. Их сущность и содержание выражается именно в насущной потребности практики по разрешению вопросов баланса частных и публичных интересов, удовлетворения потребности граждан, защите их законных прав и свобод.

В современном государстве распространение в процессе конституционализации норм и принципов Конституции на административное право приводит к тому, что любая деятельность публичной администрации именно в Конституции находит свое правовое обоснование и границы, при этом данный процесс должен происходить с опорой на фундаментальные ценности, особое место среди которых занимают права, свободы и обязанности граждан [15].

Обращаясь к самому насущному вопросу, который волнует ученых-административистов, да и не только, уважаемый профессор особо отмечает, что внесенные законодателем в Конституцию РФ вопросы организации и осуществления публичной власти не коснулись самого главного - системы государственного управления, его нормативного определения, понятийной дифференциации, взаимодействия с исполнительной властью, не отражена в тексте Конституции РФ терминология управленческого характера, при этом сложно представить что категория публичная власть способна надлежащем образом выполнять функции взаимодействия различных органов, в том числе в сфере управления. При таком подходе закономерно возникает вопрос соотношения государственной и публичной власти.

По нашему мнению, на основании устоявшихся теоретических позиций, публичная власть по своему содержанию является более широким понятием, по сравнению с государственной властью, т.к. в ее содержание также входит муниципальная власть (мест- ное самоуправление), а первооснову, фундамент составляет именно народовластие.

В связи с введением в научный оборот, предназначением термина «публичная власть», по мнению Ю.Н. Старилова, становится укрепление позиций государственного управления в широком смысле данного термина, т.е. включение в его содержание практической деятельности всех органов государственной власти - исполнительной, законодательной и судебной (ст. 10 Конституции РФ). При таком подходе система государственного управления расширяет свои границы. Насколько это оправдано - покажет время. Сегодня сложно сделать какие-либо позитивные выводы, что публичная власть будет повышать значимость и эффективность публичной администрации, при этом уважаемый профессор придерживается позиции именно узкого понимания государственного управления.

Анализ положений новой редакции Основного закона позволяет констатировать, что словосочетание «государственное управление» встречается в его содержании два раза в контексте управления федеральной собственностью (ст. 71, 114 Конституции РФ), при этом уместно отметить, что Правительство РФ не осуществляет полномочия по государственному управлению и исполнению законодательства. Обращение федеральному Конституционному закону «О Правительстве Российской Федерации» [2] позволяет также утверждать, что среди полномочий Правительства в контексте государственного управления прописаны только п. 11 ст. 18 - управление федеральной собственностью и п. 8 ст. 19 - управление государственным внутренним и внешним долгом Российской Федерации. Уместно отметить, что этот список является исчерпывающим.

По мнению автора настоящих строк есть все основания говорить о том, что публичная власть есть отражение насущной потребности современных реалий развития Российской государственности, которая нашла выражение в политической установке руководства государства, направленной на укрепление и развитие демократических начал российской государственности, в которых личность, институты гражданского общества составляют фундамент и первооснову публичной власти. При таком подходе, на наш взгляд, представляется целесообразным обратиться к зарубежному опыту, который обуславливает справедливость высказанных нами положений.

Следует согласиться с авторитетным мнением профессора А.Б. Зеленцова, что в качестве одного из важнейших итогов конституционализации административного права в современной зарубежной литературе рассматривается смена парадигмы административно- 
го права и переход от «конституционного институционализма к конституционному антропоцентризму'». В рамках новой парадигмы публичная администрация перестает быть начальной точкой отсчета, и ее место занимает человеческая личность, реализация которой оправдывает смысл существования самой публичной администрации.

Эта тенденция находит отражение в научной и учебной литературе, ориентирующейся на превращение административного права из права власти в право граждан [7]. При таком подходе предназначение административного права прежде всего заключается в обеспечении органами публичной власти прав и свобод человека и гражданина, удовлетворение его потребностей, в том числе и по оказанию государственных услуг в условиях развития информационных технологий и цифровой трансформации сервисной функции публичной власти, а также реализации задач и функций государства во всех сферах жизнедеятельности.

Предпосылки развития сервисного подхода применительно к российскому государству можно обнаружить в либертарной теории права, разработанной B.C. Нерсесянцем - советским и российским правоведом, академиком РАН, некогда заведующим сектором истории государства, права и политических учений Института государства и права РАН.

Либертарно-юридический подход исходит из различения права и закона. Одним из основных постулатов этой теории выступает утверждение о том, что право должно принадлежать обществу, а закон - государству. При этом общество, самостоятельно определяет, как и когда обращаться к государству за реализацией своих прав, а государство должно лишь обеспечивать законность процедур обращения, основываясь на принципах равенства, свободы и справедливости (триединство по В.С. Нерсесянцу) [8].

Иными словами, краеугольным камнем сервисной философии государства является «ориентация госслужбы на гражданина, его потребности и интересы» [11].

Как нами отмечалось ранее в стране перманентно проводится административная реформа, тесно увязанная с сервисным подходом Правительства к публичному администрированию: идёт оптимизация и реформирования институтов развития, проводится цифровая трансформация в социальной, экономической и иных сферах.

Антропоцентризм предписывает ставить феномен человека во главу всей прочей жизни. Известное выражение Протагора «Человек есть мера всех вещей» является ключевой фразой антропоцентризма греческой философии. https://ru.wikipedia.org/wiki/Антропоцентризм.
Законодатель уже сегодня предпринимает конкретные, хотя и робкие шаги в статуировании правового института государственного администрирования, нормативно закрепляя при этом реординарные отношения, возникающие при оказании гражданам, при их обращении в органы публичной администрации, сервисных услуг во всех сферах жизнедеятельности.

На основание вышеизложенного, представляется целесообразным сделать некоторые умозаключения.

Анализ действующего законодательства, правоприменительной практики деятельности публичной администрации, а также проведенного нами исследования проблематики публичного администрирования позволяет констатировать, что органы публичной власти осуществляют реализацию задач и функций государства во всех сферах жизнедеятельности. Именно такая деятельность, осуществляемая на основании и во исполнение закона по защите прав и свобод человека и гражданина, а также реализации задач государства в социально-экономической, правоохранительной и иных сферах именуется публичным администрированием.

При таком подходе нами предлагается новое научное направление в теории науки административного права - публичное администрирование, которое идет в контексте конституализации предмета административного права современной России, регулирующего общественные отношения от чисто управленческих - государственно-властных (императивных) во всех сферах жизнедеятельности нашего общества до реординарных (сервисных) отношений по оказанию гражданам по их инициативе государственных услуг, а также восстановлению нарушенных прав граждан неправомерными действиями должностных лиц публичной администрации [4].

При этом такая деятельность не является прерогативой только исполнительной власти, а осуществляется органами публичной власти всех уровней - законодательной, судебной и исполнительной. Законодатель прописывает правоустановления, направленные на развитие и реализацию прав и свобод человека и гражданина; судебные органы осуществляют защиту, а также восстановление прав и свобод граждан, нарушенных незаконными действиями должностных лиц публичной администрации. Исполнительная власть осуществляет управленческие функции публичного администрирования по реализации задач и функций государства во всех сферах жизнедеятельности, в том числе по обеспечению поступательного развития в социально-экономической сфере, обеспечению национальной безопасности, а также оказанию сервисных услуг гражданам по их инициативе. 
1. Конституция Российской Федерации.

\section{ЛИТЕРАТУРА}

2. Федеральный Конституционный закон от 06.11.2020 № 4-ФК3 «0 Правительстве Российской Федерации» // http://publication.pravo.gov.ru/Document/ View/0001202011060001

3. Федеральный закон от 8 декабря 2020 г. № 394-Ф3 «0 Государственном Совете Российской Федерации» // СЗ РФ. 2020 . № 50 (часть ІІІ) ст. 8039.

4. Воронов А.М. К вопросу правовой регламентации государственного администрирования // Административное право и процесс. 2018. № 4. С. $38-43$.

5. Гоголев А.М. Некоторые тенденции и закономерности становления и развития государственного администрирования //Административное право и процесс. 2018. № 2. С. 19-25.

6. Воронов А.М., Гоголев А.М. Правовое администрирование на пороге четвертой промышленной революции В сборнике: Российская правовая система в условиях четвертой промышленной революции. Материалы VI Московского юридического форума XVI Международной научно-практической конференции. В 3-х частях. 2019. С. 109-115.

7. Зеленцов А.Б. Конституционализация административного права в России: теоретические проблемы // Административное право и процесс. 2018. № 12. С. 12-21.

8. Нерсесянц В.С. Национальная идея России во всемирно-историческом прогрессе равенства, свободы и справедливости. Манифест о цивилизме.М.: НОРМА-ИНФРА-М, 2001.- - 613.

9. Попов Л.Л. Развитие теории административного права в современных условиях» // Административное право и административный процесс. 2020. № 7. С. 21-24.

10. Старилов Ю.Н. Действительно ли наступила эпоха ренессанса государственного управления в России? К юбилею профессора Льва Леонидовича Попова // Административное право и административный процесс. 2020. № 7. С 25.

11. Национальные интересы: приоритеты и безопасность: журнал / ред. Ю.П. Хрусталев. — Москва: Финансы и кредит, 2014. —№ 13/24. —807с.

12. Civil society of modern russia: problems of implementation of constitutional rights and freedoms Voronov A.M., Kobzar-Frolova M.N., Redkous V.M., Gogolev A.M. International Journal of Economics and Business Administration. 2019. T. 7. № S1. C. 243-251.

13. Restrepo Medina Manuel Alberto El derecho administrativo enlos albores del siglo XXI. Bogota / Ed. Universidad de Rosario. 2007. P. 41.

14. Enrique Linde Paniagua Fundamentos de Derecho Administrativo. Del derecho del poder al derecho de los ciudadanos. 4 ed. Madrid. 2012. P. 96-99.

15. https://www.elibrary.ru/item.asp?id=36496573

(c) Воронов Алексей Михайлович ( alex_voronoff@mail.ru ).

Журнал «Современная наука: актуальные проблемы теории и практики» 